\title{
Studying the Effect of Tio2 Nanoparticles on Seed Germination Characteristics of Ziziphora Clinopodioides Lam
}

\author{
Reyhaneh Azimi i* and Mohammad Kia Kianian² \\ ${ }^{1}$ Faculty of Rangeland and Watershed Management, Gorgan University of Agricultural Science and Natural Resources, Iran \\ ${ }^{2}$ Assistant professor of Desert Studies Faculty, Semnan University, Iran
}

*Corresponding author: Adel A El Lahamy, National Institute of Oceanography and Fisheries, Fish Processing Technology Laboratory, Egypt.

Received Date: March 13, 2020

Published Date: September 30, 2020

\begin{abstract}
Improvement in the rate and amount of germination of seeds has a very important effect on the establishment of primary seedlings and the increase of rangeland production. The rapid and uniform germination of seeds leads to the successful establishment of plants. The use of nanoscale materials can help germinate faster seeds. Therefore, in this study, the effects of TiO2 nanoparticles in concentrations of 0, 10, 20, 30, 40, 60 and 80 $\mathrm{mg} / \mathrm{L}$ on the rate and speed of seed germination of Ziziphora clinopodioides Lam. paid. This design was carried out in a completely randomized design with four replications for 20 days at a constant temperature of $20^{\circ} \mathrm{C}$ under 12 hours of light and 12 hours of darkness at the Germinator of Natural Resources Faculty of the Ferdowsi University of Mashhad. The results showed that germination percentage of treated seeds with Ti02 nanoparticles increased to $23 \%$ ppm compared to control treatment. Also, in other concentrations of other nanoparticles, there was a positive effect on speed and germination percentage, so that the effect of different concentrations of nanoparticles on germination characteristics of Ziziphora clinopodioides Lam. seeds was significant. The highest germination percentage was observed in the concentration of $30 \mathrm{ppm}$ and the lowest germination rate at 30 and $20 \mathrm{ppm}$ concentrations. In high concentrations of TiO2 nanoparticles, no positive effects were observed on the germination characteristics of seed Ziziphora clinopodioides Lam. To conclude the use of $\mathrm{TiO} 2$ nanoparticles can be improved by improving the seed germination properties of the medicinal plant Ziziphora clinopodioides Lam. that cause increases plant's establishment in natural areas.
\end{abstract}

Keywords: Nanoparticles, Tio2, Germination, Ziziphora clinopodioides Lam

\section{Introduction}

Nanotechnology research is the background of advanced technology, which has led to the rapid development of electronic science, biotechnology, medicine, space science and defense industries. So far, few studies have been done on the effects and mechanisms of nanoparticles on plant growth [1]. Examples of the unique properties of nanoparticles include a very high specific surface area, high surface energy, and quantum imprisonment. These unusual properties may even affect their fate and environmental behavior in both mass and non-nanoscale materials [2]. Plants, ex cept for the foundation of all ecosystems, play a crucial role in the fate and transfer of nanoparticles in the environment through absorption and bioaccumulation. Silicon oxide and titanium dioxide are the most commonly used nanoparticles used in the industry. Of course, some of them are also used in agriculture and natural resources. Below we will investigate several studies on the role of these nanoparticles in the germination of different plant species.

Among different methods, nanoparticles (NPs) of different metal oxides by absorbing water, oxygen and nutrients and having the 
antimicrobial properties can affect seed germination percentage, improve growth, dry weight, photosynthesis, chlorophyll biosynthesis, and plant metabolism [3]. Thus, soaking seeds in NP solution can be used as an option to increase seed germination percentage. The application of 100\% TiO2-NP treatment increased seed germination percentage, germination index, germination energy, vigour index, seedling height and fresh weight of Pinus tabulaeformis Carrière [4]. The effect of silver NPs on Boswellia ovalifoliolata N.P. Balakrishnan \& A.N. Henry caused an increase and acceleration of the seed germination percentage [5].

Abdel Latef, et al. (2017) [6] in a research titled " Titanium Dioxide Nanoparticles Improve Growth and Enhance Tolerance of Broad Bean Plants under Saline Soil Conditions" compared the effects of three different nTiO2 concentrations $(0 \cdot 01 \%, 0 \cdot 02 \%$ and $0.03 \%$ ) with respect to plant growth and stress responses. The $0.01 \%$ nTiO2 application significantly increased shoot length, leaf area and root dry weight of plants under normal conditions.

Feizi, et al. (2012) [7,8] concluded in a study titled " Effects of various concentrations of nanoparticles and non-nano-titanium dioxide on seed germination and seedling growth of fennel", which showed that germination percentage of seeds was significantly increased in treatment Application of concentration of $60 \mathrm{mg} / \mathrm{l}$ titanium oxide nanoparticles (76\%) increased compared to other treatments and control (54\%). The average germination time improved by application of nanoparticles with a concentration of $40 \mathrm{mg} / \mathrm{L}$ compared to the control by about 31\%, while non-nano particles improved the mean germination time by only $21 \%$. In general, the use of titanium dioxide nanoparticles as an option for seed that has a germination problem and a low germination percentage can be used. Also, Feizi et al. (2013) [9], in another study titled "The effects of plant and native titanium dioxide on the fennel," showed that with the concentration of TiO2 nanoparticles at 0 $5,20,40,60$ and 80 After 14 days of inoculation, the germination percentage increased to $31.8 \%$ (60 ppm TiO2 nanoparticles) with non-nano TiO2 after 14 days of inoculation. The same positive effects were observed for stem dry weight and germination. Behnam, et al. (2012) [10], in a study titled "The effect of titanium nanoparticles and non-nanodioxid on germination performance of Echinacea purpurea under drought stress", concluded that the application of titanium dioxide treatment on the seeds of Echinacea purpurea in conditions without The stress on roots and length of seedling length and root length, rootstock and seedlings, seed vigor index, I and II, and mean germination time at $1 \%$ were very significant in drought stress conditions. Drought stress at 3-bar intensity did not negatively affect the most traits such as percentage and speed of germination, average daily germination and seed vigor index I and II in Sardinia. The concentration of $159 \mathrm{mg} / \mathrm{L}$ of non-nano titanium dioxide increased the length of stem, root, and seedlings compared to the control 3 times. In the face of drought stress, the application of 100 milligrams per liter of nanoparticles and non-na- no particles often improves the germination characteristics of Echinacea purpurea and can be recommended in areas with drought stress. Feizi, et al. (2013) [9] in a study titled "Comparative effects of different levels of titanium dioxide in nano and non-nano plants of Salvia officinalis L." concluded that after 21 days of inoculation, Germination increased with $60 \mathrm{mg} / \mathrm{l}$ nano-titanium dioxide and non-nano, but did not affect root and shoot length and biomass. Agheli, et al. (2016) [11], in a study titled "Silybum marianum L. seed germination induction using titanium dioxide nanoparticles and magnetic field", which was tested as a factorial experiment in a completely randomized design with three Repeated experiments were carried out and the first factor was seed treatment at different concentrations of titanium dioxide nanoparticles containing 50,10, 0 and $100 \mathrm{mg} / \mathrm{l}$, and the second factor of the treatment of seeds with a magnetic field at $0.30,60$ and 90 millitesla for 30 minutes showed that the highest percentage of seed germination in the interaction of nanoparticles of $\mathrm{TiO} 2$ nanoparticles with a concentration of $100 \mathrm{ppm}$ and intensity The magnetic field intensity was 30 millitesla and the application of titanium dioxide nanoparticles with a concentration of $50 \mathrm{ppm}$ and magnetic field intensity of 60 milliseconds. These treatments improved the germination percentage by 5.6 and 5.7 times the control treatment. Feizi, et al. (2012) $[7,8]$ showed in a study titled "The reaction of wheat seed to different concentrations of titanium dioxide nanoparticles (Ti02) compared to non-nano particles". Experimental treatments were based on seed's germination percentage and germination rate did not have a significant effect but had a significant effect on average germination time. The lowest mean germination time (MGT) was 0.89 days at a concentration of $10 \mathrm{ppm}$ nanoparticles of $\mathrm{TiO} 2$ and the highest was observed in the control treatment with 1.35 days (Table 2). Therefore, the concentration of $10 \mathrm{ppm}$ nanoparticles of non-nano TiO2 reduced the MGT content by 34\% compared to the control, while the concentration of $10 \mathrm{ppm}$ TiO2 in non-nano, MGT did not changed against the control. One-year-old seedlings of Pine (Larix elgensis) were placed in concentrations of 62, 125, $250,500,1000,2000 \mu \mathrm{l} / \mathrm{l}$ of nano silicon dioxide (SiO2) for about 6 hours. Nano treatment greatly improved the growth and quality of seedlings. Treatment with $500 \mu \mathrm{l} /$ liter had the best result, with an increased average height of $42.5 \%$, a root diameter of $30.7 \%$, a root length of $14 \%$, and the number of lateral roots of seedlings of $31.6 \%$ in comparison with control. Also, treatment with $500 \mu \mathrm{l} / \mathrm{l}$ showed the highest concentration of chlorophyll [12]. Lee, et al. (2008) [13] examined the toxicity of copper nanoparticles on beans and wheat and stated that TiO2 concentrations had a significant effect on root dry weight but did not have a significant effect on stem and seedling dry weight. Takallo, et al. (2012) [14], in a study titled "The effect of TiO2 nanoparticles on germination and cytogenetic indices of barley plant, showed that the comparison of nanoparticle treatments compared to control increased the index of chromosomal deviations of barley, whereas on other cytogenetic indices and germination traits had no significant effect. A few study has been done on 
the effects of NP-TiO2 and TiO2 on various plants such as Triticum aestivum, Zea mays, Salvia officinalis $[15,16]$. NP-TiO2 can improve the structure of chlorophyll, increase light absorbance, facilitate formation of pigments, better capture of sunlight and transfer of light energy to active electrons, chemical activities and having effect on photosynthesis [17]. Jiang, et al. (2017) [18] showed that seed germination indices markedly improved upon seed exposure to Ti02. Samadi, et al. (2014) [19] showed that TiO2 in higher concentration had pronounced effects on photosynthetic pigments while lower concentration of NP-TiO2 had significantly increased root length. root length was significantly influenced by $100 \mathrm{mg} \mathrm{L-1}$ concentration of NP-TiO2 rather than non NP-TiO2 concentrations. Pronounced effect on photosynthetic pigments (chlorophyll a and b and carotenoids) was found in $200 \mathrm{mg} \mathrm{L}-1$ concentration of TiO2 and $100 \mathrm{mg} \mathrm{L}-1$ concentration of NP-TiO2.

Mahmoodzadeh et al. (2013) in a study named as Physiological effects of TiO2 nanoparticle on wheat (Triticum aestivum) showed that NP-TiO2 at higher concentration decreased the shoot and root length of radish, rape, corn, lettuce and cucumber. Movafeghi, et al. (2018) [20] showed that The increasing concentration of TiO2-NPs led to the significant decrease in all of the growth parameters and changes in antioxidant enzyme activities. The activity of superoxide dismutase enhanced significantly by the increasing concentration of TiO2-NPs. Enhancement of superoxide dismutase activity could be explained as promoting antioxidant system to scavenging the reactive oxygen species. In contrast, the activity of peroxidase was notably decreased in the treated plants. Reduced peroxidase activity could be attributed to either direct effect of these particles on the molecular structure of the enzyme or plant defense system damage due to reactive oxygen species.

The mixing of SiO2 and TiO2 nanoparticles with the low concentration, increased nitrate reductase activity in soybean rhizosphere, resulting in increasing of soybean germination and growth [21]. It has been reported that nanoparticles can accelerate soybean germination and growth and prevent rotting by molds. Nanoparticles can enhance roots power and nitrate reductase activity and improve the root ability to absorb water and fertilizer and increase the activity of antioxidants, dismutase and catalase enzymes and improve soybean resistance to stress [22]. The remarkable effect of nanoparticles is probably due to the small size of the particles, which allows its penetration into the seed. In a study by Ivani, et al. (2012), the effect of nano silica and non-nano silicon dioxide particles on stress tolerance of Trigonella foenum-graecum seedlings, the results of the analysis of variance showed that the levels of water stress and nano and non-nano silicon dioxide treatments had a significant effect on the studied traits.

The results of Zhang, et al. (2005) [1] showed that spinach (Spinacia oleracea) old seeds germination rate was very low. Treatment with $\mathrm{TiO} 2$ increased the rate by $23 \%$, but treatment with nano TiO2 significantly increased germination rate, germination index, seedling dry weight and Vigor index of older seeds. In spinach (Spinacia oleracea), the best treatment was 5.2 per 1000 of $\mathrm{TiO} 2$ nanoparticles, with the fresh and dry weight of each plant increasing by $63 \%$ and $76 \%$, respectively against the control [1]. All treatments significantly affected germination percentage and germination rate. The highest germination percentage was observed in the seeds of titanium nanoparticles with concentrations of 30 (48\%), 40 and $20 \mathrm{mg} / \mathrm{l}$ (35\%), and the lowest rate of germination in the seeds impregnated with titanium nanoparticles with concentrations of 30 (29.9 days) and 20 (6.9 days) were observed [1]. The germination percentage of Arabidopsis thaliana seeds was affected by SiO2. A significant positive effect on rootlet length was observed on all concentrations of nano $\mathrm{Al} 2 \mathrm{O} 3$ and 400 nano SiO2 concentrations, while other concentrations, as well as nano Fe304 and $\mathrm{ZnO}$, showed inhibitory effects on root length. All concentrations of $\mathrm{ZnO}$ contained fewer leaves [23]. Khodakovskaya, et al. (2009) [24] showed that carbon nanotubes with concentrations of $10-40 \mathrm{mg} / \mathrm{l}$ increased germination and tomato growth, which is probably due to the ability of carbon nanotubes to penetrate the seed crust and stimulation of water absorption.

\section{Materials and Methods}

\section{Introducing the plant used in the experiment}

Mountain Ziziphora clinopodioides Lam. belongs to the genus Ziziphora, the plant has a height of 10 to 40 centimeters. Booty and stable, a woody base, and sometimes it has a stem of pubes with different densities. The aerial parts of the Ziziphora clinopodioides Lam. are widely used in traditional medicine and pharmaceutical industries of Iran [25]. The resistance of the mountain Ziziphora clinopodioides Lam. to drought is suitable and can be used for cultivation in arid and semi-arid regions [26]. Also, since plants have essential oils such as peppermint plants (Ziziphora clinopodioides Lam. and etc.) have a good function in semi-arid and Mediterranean regions, these plants can be considered as a commercial product for Iran and an alternative surplus product [27]. The geographical distribution of Ziziphora clinopodioides Lam. in the world is in the Eastern Balkan Peninsula, Southwest Asia and Central Asia to the Pamir Himalaya Mountains (Iran, Iraq, and the central and eastern parts of Turkey) and Africa [28]. Ziziphora clinopodioides Lam. grows in Iran in mountainous areas, rocky and deposit slopes, and steppe areas at altitudes between 800 and $3700 \mathrm{~m}$ above sea level [28].

\section{Laboratory operations}

Germination test was performed in two stages. In the first step, in order to study the quality and percentage of germination of the Ziziphora clinopodioides Lam., 25 healthy seeds of Ziziphora clinopodioides Lam. were placed in petri dish in four replicates and germination test was done with distilled water for 20 days. After 20 days of the experiment, the germination percentage of the Ziziphora clinopodioides Lam. seed was about $25 \%$ and very low. 
Therefore, different concentrations of nanoparticles were used to improve the seed germination characteristics of Ziziphora clinopodioides Lam. This experiment was carried out to evaluate the different concentrations of titanium nanoparticles on the germination traits of Ziziphora clinopodioides Lam. seed. For this purpose, 7 treatments containing different concentrations of 0,1000 , $2000,3000,4000,6000$ and $8000 \mathrm{mg} / \mathrm{l}$ nanoparticles of titanium particles were performed in a completely randomized design with four replications. The seeds of Ziziphora clinopodioides Lam. were obtained from Khorasan Razavi Natural Resources Office. The titanium dioxide nanoparticle powder was as AEROXIDE ${ }^{\circledR}$ TiO2 P25, that prepared from Evonik DegussaGmbH company in Germany The purity of nanoparticle powder was $99.8 \%$, the average particle size was $21 \mathrm{~nm}$ and its specific surface area was $50 \mathrm{~m} 2 / \mathrm{g}$ (Figures 1 to 4). Non-nano iron oxide was prepared from AppliChem GmbH Germany with a purity of $99 \%$ and a particle size of about 1 micrometer. Before the experiment, the size of the nanoparticles was determined by an STM tunnel microscope (STM) at the Central Laboratory of Ferdowsi University of Mashhad. Also, purity and their compounds were determined by X-ray diffraction (XRD) at Damghan University of Science.

In order to obtain the desired concentrations, we first weighed the nanoscale materials in distilled water. Ultrasound bath was used for 20 minutes to prepare a uniform suspension. $2 \mathrm{ml}$ of prepared suspension was placed in per petri dish along with 25 seeds. In the control group, $2 \mathrm{ml}$ of distilled water was added. In the next steps, if necessary, only distilled water was added to the dishes. Seed scratching treatment was performed at $4^{\circ} \mathrm{C}$ for one week (ISTA, 2009). This experiment was carried out at germinator of the Faculty of Natural Resources and Environment of Ferdowsi University of Mashhad at a temperature of 20 centimeters under 12 hours of light and 12 hours of darkness. To prevent evaporation of the extract and loss of moisture, Petri dishes port were laid and placed in plastic. The germinated seeds were counted and recorded daily. Seed counting continued until 20 days after starting germination. Data and daily measurements were entered into Excel spreadsheet software and after processing, statistical analysis of data was done by SPSS18 and Minitab16 softwares and the meanings were compared by Duncan's multiple domain tests at 5\% probability level.

\section{Data Analysis}

The following equations were used to determine the rate of germination from the formula of Maguire (1982) and the mean germination time (MGT) [29]:

Germination rate $(G R)=(a / 1)+(b-a / 2)+(c-b / 3)+\ldots . .+(n-n-$

$$
1 / \mathrm{N}) \quad \text { Equation (1) }
$$

In which, $\mathrm{GR}$, the germination rate according to germinating seed per day, a, b, c, and $\mathrm{n}$ represents the number of germinated seeds after 1, 2, 3 and $\mathrm{N}$ days after starting to absorb water.

$$
\mathrm{MGT}=\Sigma \mathrm{F}(\mathrm{X}) / \Sigma \mathrm{F} \quad \text { Equation (2) }
$$

In this equation, MGT, the average germination time (day), F: The number of new seeds germinated on the day of counting Xi and $\mathrm{X}$ is the day of counting. In this experiment, Mean daily germination, Pick value and Germination value was calculated from the following equations [30]:

Daily germination average $(\mathrm{MDG})=$ Germination percent $/$ Total days of experiment Equation (3)

maximum value (PV) (GV) = highest number of germinated seeds per day/germination day Equation (4) germination value= $\mathrm{PV} \times \mathrm{MDG} \quad$ Equation (5)

\section{Results and Discussion}

In Figure 1-4, it can be seen an image of the size of the titanium dioxide nanoparticles, using a tunneling scanning microscope (STM), a topographic image of the titanium dioxide nanoparticles, using a tunnel scanning microscope (STM), illustration of the size of the non-nano titanium dioxide particles using Scanning electron microscopy (SEM) and X-ray diffraction spectrum (XRD) of titanium dioxide nanoparticles.

(Figure 1-4)

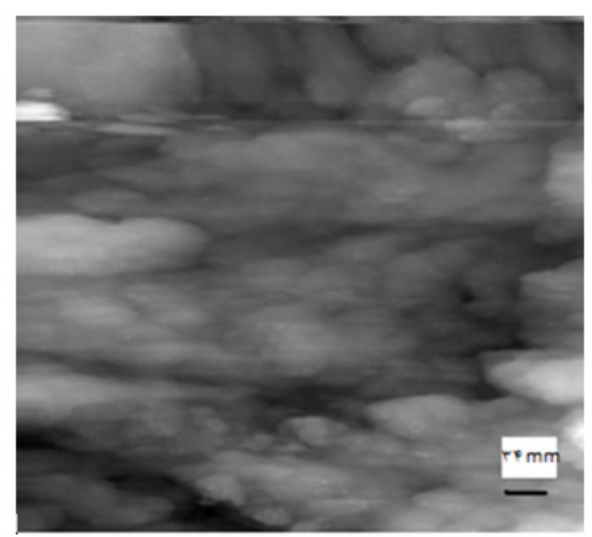

Figure 1: TiO2 nanoparticle size image by using tunneling scanning microscopy (STM). 


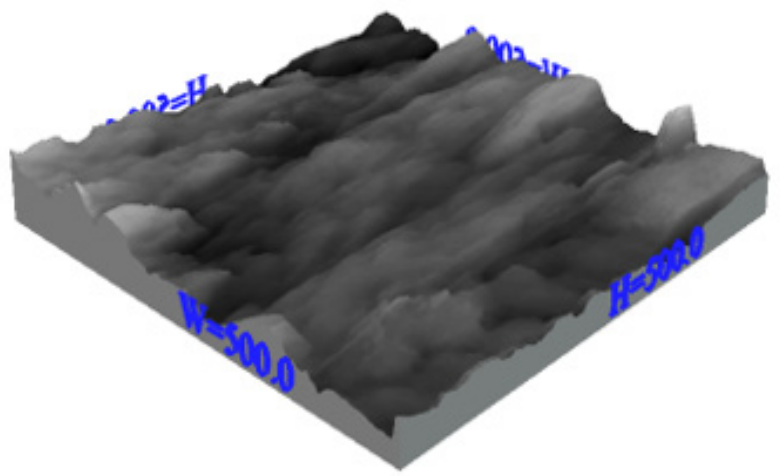

Figure 2: The topographic image of TiO2 nanoparticles using a tunneling scanning microscope (STM).

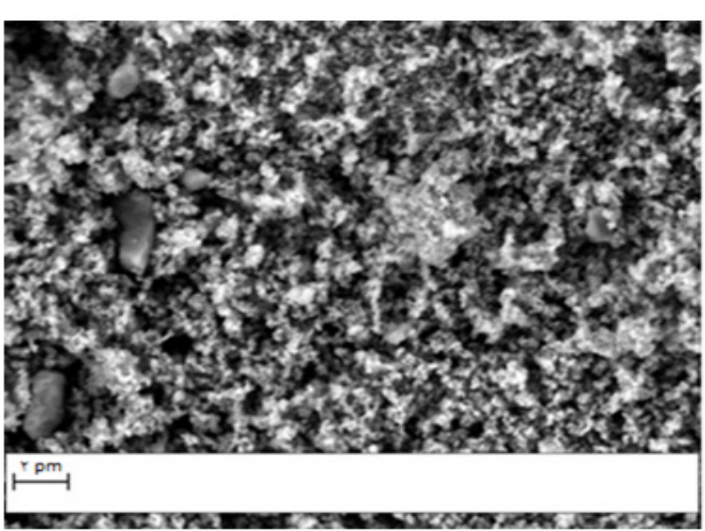

Figure 3: Non-nano TiO2 Particle Size Using Electron Scanning Microscopy (SEM).

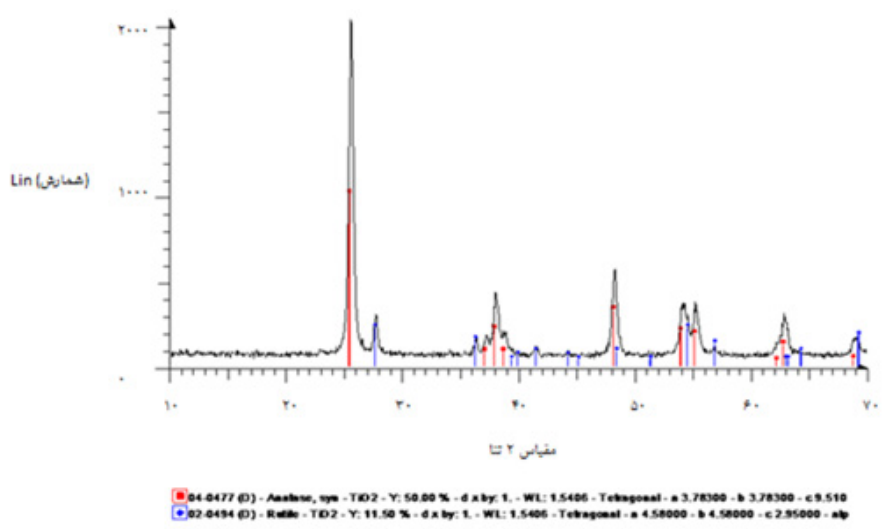

Figure 4: X-ray Spectrum (XRD) of TiO2 Nanoparticles.

The results of the analysis of variance showed that different concentrations of titanium nanoparticles had a significant effect on seed germination characteristics of Ziziphora clinopodioides Lam. Based on the results, different concentrations of titanium nanoparticles showed a significant effect on germination percentage, germination rate at $1 \%$ and $5 \%$ probability levels Table 1 . Also, the comparison of the mean of different concentrations of titanium nanoparticles on the characteristics of germination of Ziziphora clinopodioides Lam. seed is given in Table 2.

\section{(Table 1)}

In order to reduce the amount of data in the table of analysis of variance, only the mean square of the data and significant levels were used at the probability level of 1 and $5 \%$.

\section{(Table 2)}

The best rate of germination was observed at concentrations of 20, 30 and $40 \mathrm{mg}$ Table 2. The concentration of $30 \mathrm{ppm}$ of nanoparticles had the greatest effect on improving seed germi- 
nation properties of Ziziphora clinopodioides Lam. Therefore, it seems that titanium nanoparticles can be one of the treatments to improve germination properties. Seed germination percentage of the control treatment was about $25 \%$, while seed germination percentage reached $48 \%$ in the seeds treated with the nano-particles solution Table 2. The seeds that were treated with nanoparticles had the best results from the observations. The maximum germination percentage and the minimum germination time were about 48 and $29.9 \%$, respectively, compared to the control. Germination speed improved from 12.23 days in control treatment to 9.29 days in nano-treated seeds (30 ppm). Germination percentage increased with increasing concentrations up to $30 \mathrm{mg} / \mathrm{l}$, and then from $40 \mathrm{mg}$, germination percentage had decreasing trend Table 2, while Feizi et al. (2013a) [9], in a study titled "Effects of different concentrations of nano and non-nano titanium dioxide on seed germination and Foeniculum vulgare seedling growth", concluded that seed germination percentage was significantly increased in the application of $60 \mathrm{mg} / \mathrm{l}(76 \%)$ than other treatments and control (54\%).

Table 1: Effect of different concentrations of titanium nanoparticles on seed germination characteristics of Ziziphora clinopodioides Lam.

\begin{tabular}{|c|c|c|c|c|c|c|}
\hline $\begin{array}{c}\text { Coefficient of Vari- } \\
\text { ations }\end{array}$ & $\begin{array}{c}\text { Degrees of } \\
\text { Freedom }\end{array}$ & $\begin{array}{c}\text { Average Germi- } \\
\text { nation Time }\end{array}$ & $\begin{array}{c}\text { Average Daily Germina- } \\
\text { tion Rate }\end{array}$ & $\begin{array}{c}\text { Maximum } \\
\text { Value }\end{array}$ & Germination Value & $\begin{array}{c}\text { Germination Per- } \\
\text { centage }\end{array}$ \\
\hline Nanoparticles & 6 & $4.59^{*}$ & $0.62^{* *}$ & $0.03^{* *}$ & $0.25^{* *}$ & $247.81^{* *}$ \\
\hline Error & 21 & 1.56 & 0.02 & 0.004 & 0.01 & 5.9 \\
\hline
\end{tabular}

Note: ns, ${ }^{*}$, and ${ }^{* *}$ indicate a none-significant and significant difference at the probability level of $5 \%$ and $1 \%$ respectively.

Table 2: Mean comparison of different concentrations of titanium nanoparticles on seed germination characteristics of Ziziphora clinopodioides Lam.

\begin{tabular}{|c|c|c|c|c|c|}
\hline $\begin{array}{c}\text { Germination } \\
\text { Percentage }\end{array}$ & $\begin{array}{c}\text { Average Germina- } \\
\text { tion Time }\end{array}$ & $\begin{array}{c}\text { Average Daily Germina- } \\
\text { tion rate }\end{array}$ & $\begin{array}{c}\text { Maximum } \\
\text { Value }\end{array}$ & $\begin{array}{c}\text { Germination } \\
\text { Value }\end{array}$ & Amount Ti02 (ppm) \\
\hline $25 \mathrm{~d}$ & $12.23 \mathrm{a}$ & $1.25 \mathrm{~d}$ & $0.23 \mathrm{bc}$ & $0.28 \mathrm{c}$ & 0 \\
\hline $27 \mathrm{~cd}$ & $11.42 \mathrm{ab}$ & $1.35 \mathrm{~cd}$ & $0.19 \mathrm{c}$ & $0.25 \mathrm{c}$ & 10 \\
\hline $35 \mathrm{~b}$ & $9.6 \mathrm{bc}$ & $1.75 \mathrm{~b}$ & $0.3 \mathrm{~b}$ & $0.53 \mathrm{~b}$ & 20 \\
\hline $48 \mathrm{a}$ & $9.29 \mathrm{c}$ & $2.4 \mathrm{a}$ & $0.4 \mathrm{a}$ & $0.95 \mathrm{a}$ & 30 \\
\hline $35 \mathrm{~b}$ & $10.51 \mathrm{abc}$ & $1.75 \mathrm{~b}$ & $0.24 \mathrm{bc}$ & $0.42 \mathrm{bc}$ & 40 \\
\hline $28 \mathrm{~cd}$ & $11.75 \mathrm{ad}$ & $1.4 \mathrm{~cd}$ & $0.17 \mathrm{c}$ & $0.24 \mathrm{c}$ & 60 \\
\hline $29 \mathrm{c}$ & $11.03 \mathrm{abc}$ & $1.45 \mathrm{c}$ & $0.21 \mathrm{bc}$ & $0.3 \mathrm{c}$ & 80 \\
\hline
\end{tabular}

Note: The numbers with the same letters in each column are not statistically significant (according to Duncan's multiple range test at $5 \%$ probability level).

Like the present study, Feizi, et al. (2013b) [15] showed that with a concentration of $\mathrm{TiO} 2$ nanoparticles, the germination percentage increased. Feizi, et al. (2012b) [8] showed which a concentration of $10 \mathrm{ppm}$ nanoparticles of TiO2, decreased MGT until 34\% relative to the control, while the concentration of $10 \mathrm{ppm}$ of TiO2 non- nanoparticles did not change the MGT value compared with the control. Also, Behnam, et al. (2013) [10] concluded that the concentration of $159 \mathrm{mgr} / \mathrm{l}$ of non-Titanium dioxide nanoparticles increased the length of stem, root, and seedlings by 3 times against the control that is compatible to the present study. The results of Lee, et al. (2008) [13] showed that toxicity of copper nanoparticles in beans and wheat that $\mathrm{TiO} 2$ concentration had a significant effect on root dry weight, but no significant effect was observed on stem and seedling dry weight, that is compatible to the present study. Zhang et al. (2005) [1] showed that increased germination and dry weight are probably due to increased absorption of mineral nutrients and the photosynthesis process catalyzed by $\mathrm{TiO} 2$ nanoparticles. The remarkable effect of nanoparticles is probably due to the small size of the particles, which allows it to penetrate into the seed during the treatment period, that is compatible to the present study. Lu, et al. (2002) [21] reported that the mixture of $\mathrm{SiO} 2$ and $\mathrm{TiO} 2$ nanoparticles increased at low concentration of nitrate reductase in soybean rhizosphere, resulting in increased germination and soybean growth. According to Zhang et al. (2005) [1], nano TiO2 treatment significantly increased germination rate, germination index, seedling dry weight and Vigor index of older seeds, that is compatible to the present study. It is possible that superoxide and hydroxide ions increase the permeability of the seed and facilitate the entry of water and oxygen into the cell, and thus aggravate the seed germination metabolism [31-34]. In addition, the entry of TiO2 nanoparticles into cells can produce oxidation-reduction reactions through radical superoxide ions during germination in the dark, leading to the release of free radicals in the germinating seeds. The oxygen produced in such a process can be used for breathing, which will further stimulate germination, that is compatible to the present study.

All treatments of this study significantly affected germination percentage and germination rate. The highest germination percentage was observed in the seeds of titanium nanoparticles with concentrations of 30 (48\%), 40 and $20 \mathrm{mg} / \mathrm{l}$ (35\%), and the lowest germination rate were observed in the seeds impregnated with titanium nanoparticles with concentrations of 30 (29.9 days) and 20 (6.9 days).

\section{Conclusion}

Improvement in the rate and rate of seed germination has a very important effect on the establishment of primary seedlings 
and the increase of rangeland production. Rapid and uniform germination of seeds leads to the successful establishment of plants. The use of nanomaterials can help seeds to germinate faster. Therefore, in this research, the effects of TiO2 nanoparticles in concentrations of $0,10,20,30,40,60$ and $80 \mathrm{mg} / \mathrm{l}$ on the rate and speed of seed germination of Ziziphora clinopodioides Lam were studied. The effect of different concentrations of titanium nanoparticles on germination percentage and germination rate of Ziziphora clinopodioides Lam. seed was significant at $1 \%$ and $5 \%$ probability level. Titanium nanoparticles in the concentration of 30 and $20 \mathrm{mg} / \mathrm{l}$, stimulating effect and in higher concentrations had an inhibitory or neutral effect on seed germination of Ziziphora clinopodioides Lam. High concentrations of titanium nanoparticles in the germination stage had a negative effect on MGT, and the best and suitable concentration was used to stimulate growth and germination of $30 \mathrm{mgr} / \mathrm{l}$ of nanoparticles. These results indicate that the use of TiO2 nanoparticles can increase the establishment of this plant in natural areas by improving the seed germination properties of the Ziziphora clinopodioides Lam. medicinal plant.

\section{Acknowledgement}

None.

\section{Conflict of Interest}

Author declare no conflict of interest.

\section{References}

1. Zhang L, Hong F, Lu S, Liu C (2005) Effect' of nano-TiO2 on strength of naturally aged seeds and growth of Spinach. Biol Trace Elem Res 104(1): 83-92.

2. Thakkar KN, Snehit S, Mhatre MS, Rasesh Y, Parikh MS (2009) Biological synthesis of metallic nanoparticles. Nanomedicine: Nanotechnology Biology and Medicine 6(2): 257-262.

3. Rezaei F, Moaveni P, Mozafari H (2015) Effect of different concentrations and time of nano $\mathrm{TiO} 2$ spraying on quantitative and qualitative yield of soybean (Glycine max L.) at Shahr-e-Qods, Iran. Biological Forum an International Journal 7: 957-964

4. Yinfeng X, Xiaohua Y (2009) Effects of nano-meter TiO2 on germination and growth physiology of Pinus tabulaeformis. Acta Botanica BorealiOccidentalia Sinica 29: 2013-2018.

5. Savithramma N, Ankanna S, Bhumi G (2012) Effect of nanoparticles on seed germination and seedling growth of Boswellia ovalifoliolata-an endemic and endangered medicinal tree taxon. Nano Vision 2: 61-68.

6. Abdel Latef AA, Ashish Kumar S, Abd El-sadek MS, Kordrostami M, Phan Tran LS (2017) Titanium Dioxide Nanoparticles Improve Growth and Enhance Tolerance of Broad Bean Plants under Saline Soil Conditions. Land degradation and development 29(4): 1065-1073.

7. Feizi H, Rezvani Moghadam P (2012a) Effects of different concentrations of nano and non-nano-titanium dioxide on seed germination and fennel seedling growth. The First National Conference on the Use of Medicinal Plants in the LifeStyle and Traditional Medicine, Torbat Heydarieh University.

8. Feizi H, Rezvani Moghaddam P, Fatouet A, ShahTahmasbi N (2012b) The reaction of seed germination to different concentrations of titanium dioxide nanoparticles (TiO2) in comparison with non-nanoparticles. Second national conference on seed science and technology. The Islamic Azad University of Mashhad.
9. Feizi H, Kamali M, Jafari L, Rezvani Moghaddam P (2013a) Phytotoxicity and stimulatory impacts of nanosized and bulk titanium dioxide on fennel (Foeniculum vulgare Mill). Chemosphere 91(4): 506-511.

10. Behnam H, Feizi H, Ali Panah M, Faravani (2012) Effect of Titanium Neotropic and Non-Nano Dioxide on Germination Performance of Falcariae under Drought Stress. Master thesis, Faculty of Agriculture and Natural Resources, Torbat Heydarieh University, Iran.

11. Agheli, N, Ali Akbarkhani Z, Behnam H, Feyzai H (2015) Silybum marianum L. seed germination induction using titanium dioxide nanoparticles and magnetic field. The first national conference of aromatic and medicinal herbs. Gonbad Kavous University, Iran.

12. Lin BS, Diao SQ Li CH, Fang LJ, Qiao SC, et al. (2004) Effects of TMS (nanostructured silicon dioxide) on the growth of Changbai Larch seedlings. Journal for Research CHN 15: 138140.

13. Lee WM, An YJ, Yoon H, Kwbon HS (2008) Toxicity and bioavailability of copper nanopar $\neg$ ticles to the terrestrial plants mung bean (Phaseolus radiatus) and wheat (Triticum aestrivum): plant agar test for waterinsoluble nanoparticles. Environ Toxic Chem 27(9): 1915-1921.

14. Takallo S, Davoudi D, Omidi M, Ebrahimi MA, Roozbeh F, et al. (2012) Effect of TiO2 nanoparticles on germination and cytogenetic indices of barley. Journal of Agricultural Biotechnology 5(1).

15. Feizi H, Amirmoradi S, Abdollahi F, Jahedi Pour S (2013b) Comparative effects of nanosized and bulk titanium dioxide concentrations on medicinal plant Salvia officinalis L. Annual Research \& Review in Biology: 3(4): 814-824.

16. Morteza E, Moaveni P, Aiabadi Farahani H, Kiyani M (2013) Study of photosynthetic pigments changes of maize (Zea mays L.) under nano TiO2 spraying at various growth stages. Springer Plus. 2(1): 247.

17. Chen L, Zhou L, Liu Y, Deng S, Wu H, Wang G (2012) Toxicological effects of nanometer titanium dioxide (nano-TiO2) on Chlamydomonas reinhardtii. Ecotoxicol Environ Saf 84: 155-162.

18. Jiang F, Shen Y, Ma C, Zhang X, Cao W, et al. (2017) Effects of TiO2 nanoparticles on wheat (Triticum aestivum L.) seedlings cultivated under super-elevated and normal CO2 conditions. PLoS One 12(5): e0178088.

19. Samadi N, Yahyaabadi S, Rezayatmand Z (2014) Effect of TiO2 and TiO2 Nanoparticle on Germination, Root and Shoot Length and Photosynthetic Pigments of Mentha Piperita. International Journal of Plant \& Soil Science 3(4): 408-418.

20. Movafeghi A, Khataee A, Abedi M, Tarrahi R, Dadpour M, et al. (2018) Effects of TiO2 nanoparticles on the aquatic plant Spirodela polyrrhiza: Evaluation of growth parameters, pigment contents and antioxidant enzyme activities. J Environ Sci (China) 64: 130-138.

21. Lu CM, Zhang CY, Wu JQ, Tao MX (2002) Research of the effect of nanometer on germination and growth enhancement of Glycine max and its mechanism. Soybean Science 21(3): 168-172.

22. Liu XM, Zhang FD, Zhan SQ, He XS, Fang R, et al. (2005) Effects of nanoferric oxide on the growth and nutrients absorption of peanut. Plant Nutr and Fert Sci 11: 14-18.

23. Lee CW, Mahendra S, Zodrow K, Li D, Tsai Y, et al. (2010) Developmental phytotoxicity of metal oxide nanoparticles to Arabidopsis thaliana. Environ Toxicol Chem 29(3): 669-675.

24. Khodakovskaya M, Dervishi E, Mahmood M, Xu Y, Li Z, et al. (2009) Carbon nanotubes are able to penetrate plant seed coat and dramatically affect seed germination and plant growth. ACS Nano 3(10): 3221-3227.

25. Khirkhah M (2011) Evaluation of ecological characteristics of perennial Ziziphora clinopodioides Lam. (Ziziphora clinopodioides Lam.) Species in natural areas and the feasibility of domestication in a low farming system. Master thesis, Ferdowsi University of Mashhad, Iran.

26. Azizi G (2004) Effect of drought stress and degradation on some quantitative characteristics of Zataria multiflora, Ziziphora 
clinopodioides Lam., Thymus vulgaris and Teucrium polium. Master thesis Ferdowsi University of Mashhad.

27. Naghdabadi HA, Yazdani D, Nazari F, Sajed MAS (2002) Seasonal variations of yield and compounds of Thymus vulgaris essential oil in different planting densities. Quarterly Journal of Medicinal Plants 5: 5156.

28. Jam Zadeh Z (2009) Thymees and Sardines of Iran. Publications of the Institute of Forestry and Rangelands of the Country.

29. Matthews S, Khajeh Hosseini M (2007) Length of the lag period of germination and metabolic repair explain vigor differences in seed lots of maize (Zea mays). Seed Science Technology 35(1): 200-212.

30. Hartmann HT, Kester DE, Davies FT (1990) Plant propagation: principles and practices. Prentice Hall, Englewood Cliffs, New Jersey, p.647.
31. Joliano BO (1993) Rice in human nutrition. FAO Food and nutrition series, no. 26, Ruma.

32. Lin D, Xing B (2007) Phytotoxicity of nanopartiาcles: inhibition of seed germination and root growth. Environ Pollut 150(2): 243-250.

33. Maguire ID (1982) Speed of germination- Aid in selection and evaluation for seedling emergence and vigor. Crop Science 2(2): 176-177.

34. Zhu H (2008) Uptake, translocation, and accumulation of manufactured iron oxide NPs by pumpkin plants. J Environ Monit 10(6): 713-717. 